\title{
Concepções sobre a Aprendizagem Baseada em Problemas: um Estudo de Caso na Famema
}

\section{Conceits about Problem Based Learning: a Case Study at Famema}

\author{
Magali Aparecida Alves de Moraes $^{1}$
}

Eduardo José Manzini

PALAVRAS-CHAVE:

- AprendizagemBaseada em Problemas;

- Educação

- Educação Médica;

- Ensino;

- Aprendizagem;

- Currículo;

- Docentes de Medicina.

KEY-WORDS:

- Problem Based Learning;

- Education;

- Medical Education;

- Teaching;

- Learning;

- Curriculum;

- Faculty, Medical.

Recebido em: 07/10/2005

Reencaminhado em: 29/04/2006

Aprovado em: 04/09/2006

\section{RESUMO}

O trabalho constitui um estudo de caso que aborda as versões sobre a implementação e desenvolvimento da Aprendizagem Baseada em Problemas (ABP) na Faculdade de Medicina de Marília (Famema). O objetivo da pesquisa foi analisar as concepções de docentes-gestores, docentes-tutores e estudantes da Ia série do curso de Medicina sobre essa metodologia no currículo da Famema e sua relação com a formação médica. Os dados foram coletados por meio de entrevistas semi-estruturadas. Os roteiros das entrevistas foram analisados por juízes, e um estudo piloto foi realizado para a sua adequação. As entrevistas foram realizadas com dois gestores, 12 docentes-tutores e 12 estudantes da I série do curso médico da Famema em 2002. O método utilizado para a análise das entrevistas foi o de análise de conteúdo temática. Após a elaboração das classes temáticas, estas foram avaliadas por dois juízes, e o índice de concordância com a pesquisadora foi de 94,8\% e 97,43\%, respectivamente. Foram definidas duas temáticas: a ABP na Famema, e a formação médica e a $A B P$. A análise dos dados permite considerar que: 1) o processo educacional realizado na Famema tem sido construído coletivamente; 2) o contexto de ensino-aprendizagem e da prática profissional é dinâmico e cheio de contradições e opiniões diferentes; 3) a educação permanente para os docentes é um recurso necessário, que precisa ser estendido à prática profissional dos profissionais de saúde.

\begin{abstract}
This case study approaches the different conceits existing with respect to the development and implementation of Problem Based Learning (PBL) at the Faculty of Medicine of Marilia (Famema). The aim of this study was to analyze the opinions of managers-professors, tutorial-professors and first year students of the Medical Course about this methodology in the curriculum of Famema and its relationships with medical education. Data were collected by means of semistructured interviews. The guidelines for the interviews were analyzed by referees, and a pilotstudy was carried out for adapting them. The interviewed persons were two managers, twelve tutorial-professors and twelve first year medicine students from Famema in 2002. The interviews were analyzed using thematic content analysis. Two referees evaluated the thematic categories and the level of agreement with the researcher was $94.8 \%$ and $97.43 \%$ respectively. The thematic categories were: PBL at Famema and medical education and PBL Analysis of the data allowed concluding that 1) the educational process at Famema was built collectively; 2) teaching-learning and the professional practice are dynamic contexts, with plenty of contradictions and different opinions; and 3) continued capacity building for tutorial professors is a necessary resource that should be extended to the professional practice of health professionals.
\end{abstract}




\section{INTRODUÇÃO}

No campo de investigação do ensino das ciências da saúde, tem-se questionado a utilidade dos conhecimentos e sua aplicabilidade social. Novas concepções de ensino e aprendizagem estão sendo incorporadas no contexto escolar e na prática educativa. A valorização dos estudantes, enquanto sujeitos ativos na transformação das práticas de saúde, com compromisso social e agentes (re)construtores de seus conhecimentos, constitui a mais recente abordagem nesse campo.

As instituições responsáveis pela formação dos profissionais de saúde (gestores acadêmicos, professores, pesquisadores e planejadores de saúde) têm pela frente um desafio: responder às demandas sociais e inovar ações educacionais nas escolas médicas.

O modelo hegemônico da formação médica que enfatiza as especializações, o enfoque biológico e o atendimento individual, hospitalar e curativo não responde as necessidades da população. Neste paradigma, o diagnóstico e a terapêutica têm grande relevância, e as ações de saúde são essencialmente voltadas ao indivíduo, excluindo-se delas o contexto social, histórico e ambiental. Com a criação, em 1988, do Sistema Único de Saúde (SUS) no Brasil, busca-se trocar este modelo por um outro, da determinação social. Neste contexto, passou-se a repensar a formação dos profissionais de saúde. Algumas propostas surgiram na década de 1990. Almeida as analisou e considerou a mais consistente e estruturada a que se refere à proposta UNI (Uma nova iniciativa na educação de profissionais de saúde: união com a comunidade), acrescentando que, apesar de suas debilidades, ela é a responsável pelos processos de mudança mais avançados ${ }^{1}$.

Processos de Avaliação realizados pela Comissão Interinstitucional de Avaliação do Ensino Médico (Cinaem) ${ }^{2}$ contribuíram para que se estabelecessem em 2001 as novas Diretrizes Curriculares Nacionais do Curso de Graduação em Medicina $^{3}$. Porém, para se efetivarem, estas necessitam também de políticas de saúde, articulação entre a academia, os serviços de saúde e a sociedade, e a constituição de sujeitos sociais tanto no contexto escolar quanto na prática médica.

A Faculdade de Medicina de Marília (Famema) é uma das escolas que se propôs a enfrentar esse desafio. Desde 1997, iniciou um processo de implementação e desenvolvimento do currículo médico com a utilização de uma nova metodologia, denominada Aprendizagem Baseada em Problemas (ABP).

O interesse neste estudo para a pesquisadora, que exerce função docente e assistencial como psicóloga na Famema, foi estudar a ABP, metodologia considerada inovadora na educa- ção médica, aprimorando seus conhecimentos e o exercício de sua prática profissional e, ao mesmo tempo, contribuir com a construção permanente do desenvolvimento curricular, tanto na Famema como em outras instituições de ensino que almejam a inovação curricular e de ensino-aprendizagem.

O objetivo geral deste estudo foi analisar as concepções de docentes-gestores, docentes-tutores e estudantes da 1a série do curso de Medicina sobre a ABP no currículo da Famema e sua relação com a formação médica.

A decisão de analisar as concepções dos estudantes da 1a série se deve ao fato de que, por serem os que recebem os primeiros impactos da $\mathrm{ABP}$, necessitam de maior atenção e recursos adaptativos a esse tipo de aprendizagem ${ }^{4}$. Há preocupação, por parte dos pesquisadores, com os aspectos emocionais desses estudantes diante de mais uma situação nova nesse período educacional.

Os estudantes da 1a série, em sua maioria, têm de lidar com várias mudanças, tais como a cidade, a separação de familiares e amigos. Nessa fase, eles iniciam a construção da identidade do futuro profissional médico e, ao chegarem à Famema, vêem-se diante de um currículo diferente e de um novo método de ensino-aprendizagem, a ABP. Por tudo isso, a preocupação em ouvir e analisar suas concepções motivou este estudo.

A ABP é um método de ensino-aprendizagem assentado numa aprendizagem baseada em problemas. O ensino-aprendizagem na ABP focaliza conhecimentos, habilidades, atitudes e valores. A aprendizagem é centrada no estudante, no aprender a aprender, na integração dos conteúdos das ciências, básicas e clínicas, além dos conhecimentos interdisciplinares.

A ABP surgiu pela primeira vez na Faculdade de Medicina da Universidade de McMaster, em Hamilton, província de Ontário, Canadá, em 19695.

Essa iniciativa acabou se propagando ao longo dos anos para outras escolas e países, incluindo 157 cursos e 126 instituições em 26 países. A ABP também é utilizada em outras áreas, como Direito, Arquitetura, Biblioteconomia e Economia $^{6}$.

A ABP, diferentemente do método de ensino tradicional baseado na transmissão de conhecimentos disciplinares, representa uma perspectiva do ensino-aprendizagem ancorada no construtivismo, na (re)construção dos conhecimentos, cujo processo é centrado no estudante.

Para que as aprendizagens de conhecimentos, habilidades, atitudes e valores possam ocorrer na $\mathrm{ABP}$, os estudantes são distribuídos na Famema em grupos de oito, auxiliados por um docente-tutor. O professor deixa de assumir o papel 
de transmissor dos conhecimentos e assume o papel de facilitador da aprendizagem, promovendo a (re)construção de novos conhecimentos, habilidades, atitudes e valores, a partir dos conhecimentos e experiências prévias dos estudantes.

Distribuídos em pequenos grupos nas atividades de sessões de tutoria, os estudantes se defrontam com situações ou problemas elaborados por docentes, com o objetivo de desafiar a aprendizagem em busca da compreensão e explicação do problema.

O currículo é organizado por unidades educacionais constituídas de problemas com conteúdos interdisciplinares.

Segundo Komatsu, Zanolli e Lima7 , cada problema deve refletir o cotidiano da prática profissional, antecipá-lo como acontecimento aos estudantes que se preparam para a atuação, permitindo uma reflexão contextualizada sobre aquela temática, a seleção de recursos educacionais, a busca de informações, a avaliação crítica e a aplicação.

A aprendizagem a partir dos conhecimentos e experiências prévias dos estudantes sobre o problema é importante para que (re)construam seus conhecimentos e aprendam significativamente para aplicá-los em sua prática profissional.

Aprender significativamente implica dar significado, sentido e funcionalidade ao que se aprende. Colle se refere à importância dos conhecimentos adquiridos significativamente para que "[...] possam ser efetivamente utilizados quando as circunstâncias nas quais o aluno se encontra assim o exigirem.". Segundo esse autor, o que realmente importa na aprendizagem escolar de conceitos, processos, habilidades e valores é que ela seja significativa. Para isso, é preciso estabelecer relações entre a nova informação e os conhecimentos prévios, o que gera um estado de desequilíbrio. O estudante precisa, também, estar motivado intrinsecamente para superar o estado de desequilíbrio estabelecido, e a escola deve propiciar condições para a retomada do reequilíbrio de seus esquemas de conhecimentos. Neste processo de aprendizagem, a memorização deixa de ser repetitiva e passa a ser compreensiva, tendo em vista a ocorrência de uma aprendizagem significativa.

O estudo do problema em sessões de tutoria ocorre com discussões numa seqüência estruturada de procedimentos, intitulada os passos da tutoria em $\mathrm{ABP}^{9,10,11}$. O número de passos varia de sete a dez; na Famema, em 2002, eram utilizados dez passos para atingir o estudo dos problemas.

Na Famema, a estratégia das sessões de tutoria para estudo dos problemas de saúde é acrescida por atividades na prática profissional, havendo uma intervenção ativa dos estudantes nos cenários da prática desde a 1ạ série, como cenário não só de aprendizagem, mas de intervenção profissional, numa parceria da academia com os serviços do SUS e a comunidade, supervisionada pelos docentes/assistentes.

A capacitação dos docentes da Famema foi outro investimento empreendido para implantar o currículo com a ABP, porque se entende que mudar o currículo e a metodologia não garante mudanças das concepções de ensino-aprendizagem ou das práticas pedagógicas dos professores e estudantes. Isto porque só podemos dizer que um currículo mudou efetivamente quando os professores mudaram suas práticas e alteraram suas concepções sobre ensino-aprendizagem.

Estudos sobre a $\mathrm{ABP}$ realizados por vários pesquisadores ${ }^{12-23}$ no mundo mostram a comparação da ABP com o ensino tradicional. Almeida ${ }^{24}$ destaca que, na década de 1990, a $\mathrm{ABP}$ e o ensino orientado à comunidade são vistos como abordagens mais integradoras que as tradicionais. Entretanto, são insuficientes e sujeitas a distorções, porque a ABP não pode se restringir às manifestações superficiais de fenômenos isolados, mas deve aprofundar as explicações dos problemas de saúde, discutindo-os em sua integralidade, o que requer a incorporação e o fortalecimento das ciências básicas e sociais.

A principal questão para o ensino médico não é definir o melhor ou pior método, e, sim, a intencionalidade educacional e o perfil profissional do médico que a escola pretende formar, para daí poder escolher a metodologia que contém as concepções pedagógicas de ensino-aprendizagem mais apropriadas.

Reiterando que mudar um currículo e o método de ensino-aprendizagem não garante a mudança de concepções e práticas dos professores e estudantes, foram analisadas, nesta pesquisa, as concepções sobre a ABP daqueles que estavam vivenciando esse processo de ensino-aprendizagem.

\section{MÉTODO}

\section{Aspectos éticos}

O projeto foi apreciado e autorizado pelo Comitê de Ética em Pesquisa Envolvendo Seres Humanos da Faculdade de Medicina de Marília (Famema), resolução 196/96, protocolo de estudo no 0335/00.

Os docentes-tutores, docentes-gestores e estudantes foram convidados a participar, tendo sido garantido o sigilo. Foram esclarecidos os objetivos da pesquisa e solicitado o preenchimento do termo de consentimento.

\section{Caracterização do cenário}

A Faculdade de Medicina de Marília, local onde o estudo foi desenvolvido, foi criada em janeiro de 1966, na cidade do interior do Estado de São Paulo, como Instituto Isolado de 
Ensino Superior. Em 1981, foi criado também o curso de Enfermagem.

Em 1992, a faculdade foi escolhida entre outras instituições da América Latina pela Fundação W. K. Kellogg para receber apoio técnico e financeiro para o desenvolvimento de parcerias entre academia, serviço e comunidade. O projeto desenvolvido foi denominado UNI - Uma Nova Iniciativa na Educação de Profissionais de Saúde: União com a Comunidade. O Programa UNI possibilitou à Famema a capacitação de recursos humanos e o desenvolvimento de parcerias com os serviços locais de saúde e a comunidade, ações que, para Komatsu ${ }^{25}$, foram decisivas para o movimento de mudança dos currículos de Medicina e Enfermagem.

Em 1994, a Famema foi estadualizada, e o Governo do Estado criou a Autarquia Especial da Faculdade de Medicina de Marília, ligada à Secretaria de Estado de Ciência, Tecnologia e do Desenvolvimento Econômico do Governo de São Paulo.

A implantação gradual do novo currículo iniciou-se em 1997 e vem se aprimorando, porque tem a concepção de que a construção curricular é permanente.

A Famema foi pioneira na implementação da ABP no Brasil e na América Latina. Em 1998, o curso de Medicina do Centro de Ciências de Saúde da Universidade Estadual de Londrina (UEL) também implantou um currículo com ABP.

\section{Tipo de estudo}

Realizou-se um estudo de caso com abordagem qualitativa.

\section{Sujeitos}

Os sujeitos escolhidos foram 2 docentes-gestores da implementação da ABP na Famema, 12 docentes-tutores e 12 estudantes da $1 \underline{\text { a }}$ série do curso de Medicina da Famema.

Não foi escolhido a priori um determinado número de sujeitos. O critério foi o de recorrência de conteúdo, isto é, a coleta de dados terminou quando os conteúdos das entrevistas começaram a se repetir.

Os estudantes tinham entre 18 e 23 anos, sendo que 8 deles eram do gênero feminino, todos solteiros. Dois deles tinham iniciado outro curso superior anterior ao de Medicina e não o haviam completado.

Os docentes-tutores tinham idade de 33 a 51 anos, e 7 deles eram do gênero feminino. Seis eram médicos e 6 não eram médicos. Dois dos docentes que não eram médicos concluíram o mestrado, e 1 estava cursando o doutorado. Dois dos docentes-médicos possuíam pós-doutorado, 2 mestrado e 2 especialização. A carga horária de trabalho de 10 docentes era de 40 horas semanais, e 2 deles tinham jornada de 20 horas semanais.

Os docentes-gestores eram médicos, do gênero masculino, tinham a idade de 48 e 49 anos. Um deles possuía mestrado, e o outro estava cursando doutorado. A carga horária de atividades desses docentes-gestores era de 40 horas semanais na Famema.

\section{Coleta de dados}

Para coletar os dados, inicialmente, realizou-se a identificação de documentos institucionais existentes na Famema sobre o processo de implantação da mudança curricular e da metodologia da ABP, bem como os documentos relativos à evolução deste novo currículo. Esses documentos foram importantes para contextualizar o tema em estudo e proporcionar informações sobre o caso para serem discutidas a partir dos dados coletados nas entrevistas.

As entrevistas foram realizadas em 2002 e visaram identificar as concepções dos sujeitos sobre a ABP na Famema. Optou-se pela entrevista semi-estruturada, que permite maior abertura com o entrevistado no transcorrer da coleta de informações.

Um estudo piloto foi realizado para a utilização dos roteiros de entrevistas. Estas foram gravadas em fitas de áudio e transcritas de forma literal.

Os roteiros foram analisados por dois juízes, considerando três aspectos: a) a forma das perguntas; b) seqüência das perguntas; c) abrangência do fenômeno estudado. Além disso, procedeu-se à análise das ações verbais expressas, segundo Manzini ${ }^{26}$, para identificar as intenções conscientes que se têm com a pergunta e inferir o que há de oculto nela. Essa análise facilita a inferência a respeito da temática que a pergunta traz.

Os roteiros foram considerados adequados para a coleta de dados, salvo algumas sugestões para facilitar a compreensão das perguntas.

Após o estudo piloto e do procedimento para adequação dos roteiros, foram realizadas as entrevistas com mais um docente-gestor, 11 docentes-tutores e 11 estudantes. Estas também foram gravadas e transcritas de forma literal.

\section{Análise dos dados}

O método utilizado para a análise das entrevistas baseouse na Análise de Conteúdo Temática, com ênfase na abordagem qualitativa ${ }^{27}$.

Foi elaborado um quadro com as classes e subclasses temáticas e exemplos das falas de entrevistados para serem avaliadas por mais dois juízes da área da saúde, para sua adequação. 
Para garantir o sigilo, os depoimentos dos participantes foram identificados por códigos. Os códigos expressos pela letra D seguida por números se referiram aos docentes-tutores; os docentes-gestores receberam a letra $G$, seguida por números; e os estudantes foram identificados pela letra $\mathrm{E}$, seguida por números.

Após a avaliação entre os juízes, verificou-se o índice de concordância entre os juízes e a pesquisadora, de acordo com Fagundes $^{28}$. O juiz 1 apresentou um índice de concordância com a pesquisadora de $94,87 \%$, e o juiz 2, de $97,43 \%$.

Foram definidas duas temáticas: 1) A ABP na Famema e 2) Formação Médica e a ABP.

\section{RESULTADOS E DISCUSSÃO}

\section{A ABP na Famema}

As concepções dos gestores entrevistados indicaram a ABP como "uma metodologia ativa de ensino-aprendizagem", que atribui ênfase à construção ativa do conhecimento, como justifica um dos gestores: "[...] eu tiro o professor do centro do processo de ensino, colocando-o como mais um ator e coloco os alunos, em vez de elementos passivos, como elementos ativos do processo da construção dos conhecimentos". Complementando essa concepção, o outro gestor acrescentou a importância de os estudantes estarem diante de problemas da realidade a serem estudados.

Na visão dos docentes-tutores (médicos e não médicos), a ABP seria uma metodologia ativa de ensino-aprendizagem. Nenhum dos entrevistados se referiu à sua utilização em disciplinas, mas no currículo, se contrapondo a outras experiências com a ABP que empregam essa metodologia em disciplinas. A estratégia de utilizar problemas reais ou que simulam a realidade foi considerada também como algo que pode propiciar a motivação dos estudantes para aprender e integrar os conhecimentos das ciências básicas e clínicas, além da aproximação da teoria com a prática profissional, desde a 1ạsérie.

Outro aspecto destacado por um dos docentes-tutores foi que a ABP contribui para uma educação continuada. Para ele, o estudante deverá: "[...] aprender a buscar informação, fazer análise crítica dessa informação, transformar essa informação para a prática no contexto real". A noção dessa aprendizagem continuada se contrapõe à de aprendizado como algo pronto, acabado, ou seja, fica clara a noção de aprender a aprender por toda a vida.

Os estudantes não utilizaram a denominação metodologia ativa, mas definiram a ABP com a expressão "aprender a aprender", valorizando também a construção ativa do conhecimento em vez da recepção passiva da informação.
Ao falarem sobre a ABP, alguns estudantes expressaram emoções negativas que revelaram um sentimento de solidão, por se considerarem autodidatas, atitude que não estaria coerente com o que a Famema prescreve sobre a $\mathrm{ABP}^{10}$. Esses estudantes mostraram, com tais sentimentos, a não compreensão dos papéis dos docentes neste currículo e método de ensino-aprendizagem, o que ainda poderia revelar a necessidade de maior capacitação dos docentes nos novos papéis.

A estratégia de trabalhar com pequenos grupos de estudantes foi adotada pela Famema, e os entrevistados a valorizaram para desenvolver novas atitudes, de trabalho em grupo, acrescentando, à aprendizagem de conhecimentos, mudanças de atitudes e valores compartilhados em grupos colaborativos.

A compreensão dos entrevistados, docentes-gestores e docentes-tutores a respeito da mudança do currículo da Famema inclui a necessidade de mudar para atender as necessidades da população e as necessidades de aprendizagem dos estudantes de maneira efetiva, porque o que existia não satisfazia.

Implementar um novo currículo e método de ensinoaprendizagem, como existente em outros lugares, não significa reproduzir o que lá existe, mas construir um currículo, uma prática efetivada pelos sujeitos que o constroem, pautado na filosofia de aprender por problemas, de maneira ativa, centrada no estudante e interdisciplinar.

Desta maneira, os profissionais foram tentando se reconhecer neste novo currículo que, inicialmente, esteve constituído por unidades educacionais por sistemas, que contemplavam a presença dos especialistas para a construção das mesmas. Os gestores sabiam do risco que corriam, do olhar especialista, mas reconheciam que esta era uma estratégia para a adesão inicial dos docentes ao novo currículo, até que fossem possíveis novas mudanças no desenvolvimento do currículo.

De início, os gestores relataram uma adesão inicial baixa dos docentes, atribuída a aumento de responsabilidade, descrença na postura ativa do estudante e ameaça ao poder dos docentes. Mas os docentes entrevistados relataram que, ao se aproximarem da $\mathrm{ABP}$, a opinião desfavorável mudou, apesar de compreenderem que isso não implicava, de maneira direta, uma mudança na prática educacional, como afirmou um docente-médico: "[...] eu ainda tenho um ranço desse método antigo, que, em alguns momentos, eu acabo ainda funcionando daquela forma [...]".

A reação por parte dos estudantes, segundo um gestor, foi de choque. Segundo os estudantes entrevistados, o choque inicial continuou, porém para a maioria ele foi superado: 
"[...] seis meses de adaptação é o ideal, mas agora eu consigo estudar, sei como estudar. No começo é difícil mesmo estudar". Entretanto, para alguns estudantes, sentimentos de insegurança persistiram, mesmo no segundo semestre com a $\mathrm{ABP}$, havendo relato até mesmo de uma piora. Para esses estudantes, a Famema oferece o núcleo de atendimento discente por profissionais da área de saúde mental. Os orientadores que deveriam ajudar a encontrar soluções para as dificuldades de adaptação ao método ainda mostraram fragilidades, na opinião dos estudantes, em assumirem, efetivamente, esse papel.

Alguns dos estudantes não se adaptaram ao método, como referiu também um dos docentes-tutores: “[...] não é qualquer estudante que tem o perfil para o PBL [ABP].".

Existe a crença da imaturidade do estudante como um obstáculo à adaptação, a qual concentra a responsabilidade no estudante. No entanto, quando estamos com um estudante no cenário escolar, devemos ser, enquanto profissionais de educação e saúde, mediadores de seus conhecimentos, facilitadores de estratégias que possam ajudá-lo a retomar seu equilíbrio cognitivo e emocional, para enfrentar novos desequilíbrios. Ainda que nem todos os estudantes imaturos deixem de sê-lo e se tornem independentes, autônomos, precisamos tentar encontrar estratégias que possibilitem seu desenvolvimento.

Utilizar outras estratégias que contribuam para o processo de mudanças dos estudantes e dos docentes em ABP para facilitar o desenvolvimento pessoal e profissional de ambos deve ser um dos focos de atenção dos gestores.

Os entrevistados destacaram aspectos positivos e negativos da ABP na Famema.

Os gestores possuíam uma visão mais ampla em suas avaliações sobre os aspectos considerados positivos da ABP, por se referirem a aspectos internos e externos à Famema. Tal fato é justificável porque, geralmente, são eles os representantes da Famema em outros cenários, como o político e em congressos.

Os docentes-tutores e os estudantes avaliaram os aspectos relativos à sua experiência com a ABP. Entre os aspectos destacados, está a valorização da compreensão da pessoa e não da doença, que requer articulação e integração das dimensões biopsicossociais e, desse modo, a mudança de concepção de saúde - de uma visão fortemente biologicista, para uma visão mais ampla sobre a pessoa e a sua saúde, e as relações estabelecidas com o seu contexto de vida.

Ainda nas falas de docentes e estudantes, estava presente a valorização da motivação interna para estudar os proble- mas em ABP, partindo tanto da curiosidade e interesse dos estudantes quanto da mediação do tutor.

Outro aspecto considerado positivo na ABP é que se deve aprender sempre. A aprendizagem deve ser contínua porque a escola não consegue possibilitar a aprendizagem de todos os conhecimentos construídos. É importante, então, que o estudante aprenda a aprender, a raciocinar criticamente, a identificar os erros e superá-los. Aprenda também a valorizar a comunicação com as pessoas, a ser responsável, a valorizar os contextos de vida das pessoas para poder exercer a medicina - tudo isso na ABP é facilitado pela aproximação da teoria com a prática profissional desde a 1a série.

Permeiam estas avaliações as concepções de que a saúde da pessoa não envolve só o bem-estar físico e que o médico, para cuidar de uma pessoa, precisa conhecê-la e ao seu contexto de vida, porque os conhecimentos só sobre o biológico ou sobre os tratamentos medicamentosos e/ou cirúrgicos não são suficientes. No que diz respeito à concepção de ensinoaprendizagem, o erro pode ser utilizado como um meio para aprender a buscar conhecimentos e aproximar a teoria da prática. Significa, então, romper com o paradigma de que primeiro se aprende a teoria para depois aplicá-la.

Na avaliação dos aspectos negativos da ABP na Famema, os estudantes se concentraram na falta de conteúdos teóricos das ciências básicas, conteúdos normalmente valorizados nas 1 as séries do curso médico, e explicitaram a dificuldade inicial de aprender a estudar sozinhos esses conteúdos, ou seja, de encontrar recursos para superar suas dificuldades na auto-aprendizagem. Os estudantes teriam todo o curso para aprender os conteúdos dessas disciplinas básicas, mas a sensação era de que isso não aconteceria, talvez porque a concepção subjacente de ensinoaprendizagem estaria relacionada com o fato de, primeiro, aprender as ciências básicas e, depois, as ciências clínicas; além disso, aprenderiam melhor com um docente transmitindo e não com o estudante assumindo uma postura ativa para aprender.

Um docente que não era médico apresentou preocupação com o conteúdo das disciplinas básicas, por estar sendo pontual e superficial nos problemas. No entanto, reconheceu que os estudantes que buscavam consultoria na sua área de conhecimento - parasitologia -estudavam mais do que os estudantes do ensino tradicional e em várias fontes bibliográficas. Avaliou que, na ABP, eles aprendiam com mais facilidade os conteúdos que transmitia no ensino tradicional.

No que diz respeito à avaliação cognitiva na Famema, o tipo de avaliação, com a utilização de problemas, estaria coerente com o método de ensino-aprendizagem $\mathrm{ABP}$, ao invés de ser realizada por teste de múltipla escolha (como ocorre em outros lugares). Para os estudantes da Famema, isso cau- 
saria preocupação com as avaliações para a residência, que geralmente utilizavam os testes de múltipla escolha.

Outro aspecto destacado por estudantes e docentes-tutores foi a crença na possibilidade de homogeneização dos tutores e da aprendizagem - que traria a concepção de ensinoaprendizagem por transmissão e recepção passiva - e na possibilidade de a mesma aprendizagem ser atingida por todos os que receberam determinados conteúdos.

Para os entrevistados, continuaria o desafio da integração biopsicossocial entre as unidades educacionais e dos serviços de saúde e a academia. Ainda seria preciso alcançar a interdisciplinaridade, a multiprofissionalidade e o enfoque na dimensão afetiva para melhorar o cuidado com as pessoas.

Em relação ao papel do tutor nas falas dos docentes-tutores médicos e dos que não eram médicos, esteve presente a polêmica do tutor ser ou não especialista em conteúdo, o que, nessas falas, dizia respeito à necessidade de o professor acreditar que poderia dominar os conhecimentos e conduzir os estudantes aos acertos. A crença na supremacia do conteúdo em detrimento das habilidades de aprender a aprender deve ceder espaço para cada um aprender a buscar, a selecionar e a realizar análise crítica dos conteúdos, e também aprender a se relacionar em grupo, estabelecer relações interpessoais que fortaleçam o trabalho do grupo com atitudes cooperativas e solidárias, estando aberto a receber e a fazer críticas.

Os estudantes tinham a expectativa de poder contar com tutores que não os deixassem sair com conceitos errados das tutorias, como desabafou um deles: “[...] o tutor mesmo, tá lá. $\mathrm{Eu}$ acho que se ele notar que a gente tá falando uma besteira muito grande, eu creio que ele vai parar a discussão, não vai deixar a discussão progredir". Alguns estudantes ainda sugeriram que os docentes-tutores deveriam saber o conteúdo discutido na tutoria para os questionar. Esses estudantes tinham, ainda, a concepção do papel do professor como detentor do conhecimento, existente no ensino tradicional. Os tutores que não sinalizavam os erros propiciavam mais insegurança aos estudantes da 1ạ série, que ainda não confiavam em sua capacidade de auto-aprendizagem com a facilitação do tutor, que não precisava ser um especialista no assunto, mas, segundo Komatsu ${ }^{25}$, precisaria ter a capacidade de compreensão das peculiaridades do programa educacional, da metodologia de ensino-aprendizagem, dos objetivos de aprendizagem a serem alcançados pelos estudantes na unidade, e seu envolvimento e compromisso com o grupo de tutoria. Para Barrows $^{29}$, o melhor é que o tutor trabalhe para que os estudantes possam identificar seus erros, solicitando que sempre apresentem a evidência do que estão dizendo.
$\mathrm{Na}$ ABP, o docente-tutor precisa ser o guia e orientador dos estudantes, que constroem seus conhecimentos de maneira ativa, encontrando caminhos para aprender, buscando várias fontes bibliográficas, consultorias com especialistas no conteúdo, analisando as informações, utilizando seus conhecimentos e experiências prévias, compartilhando-os no grupo e aplicando-os nos problemas que simulam a realidade e na prática em outros cenários fora da tutoria. Para o estudante, o grande impacto em relação ao papel do tutor seria conviver com docentes-tutores que nem sempre eram especialistas no conteúdo e encontrar outros caminhos para confirmar ou esclarecer dúvidas fora da tutoria na construção de seus conhecimentos. Desse modo, o papel do estudante seria diferente também daquele assumido até o cursinho para o vestibular, quando o estudante estudava o que o professor transmitia e, muitas vezes, memorizava os conteúdos sem os compreender para aplicá-los nas provas, que definiam se o estudante seria aprovado ou não.

Os estudantes da 1a série do curso médico da Famema ainda viviam o conflito de indefinição sobre o seu papel, em serem passivos ou ativos na construção de seus conhecimentos, independentes ou dependentes - conflito básico vivenciado nesta fase de desenvolvimento denominada adolescência. Caberia aos docentes adultos acompanhá-los neste período de busca de identidade adulta, de independência, autonomia e aprendizagem. Nesse sentido, os docentes necessitariam compreender a dificuldade natural desse período e o quanto ele seria difícil de ser vivido. Acreditamos ser possível ajudar a facilitar a travessia desse período evolutivo e a formação de pessoas adultas, responsáveis e compromissadas com a aprendizagem contínua e com o cuidar das pessoas.

\section{Formação médica e a ABP}

A formação médica e a ABP foi a outra temática destacada das falas dos entrevistados.

A formação médica tem sido forte e tradicionalmente centrada no biológico e, segundo Lima ${ }^{30}$, a abordagem biopsicossocial proposta por Engel veio como modelo alternativo ao modelo biológico hegemônico.

Há pelo menos trinta anos, nos fóruns de discussão e reflexão sobre a educação médica, acumularam-se os argumentos favoráveis à necessidade de mudar o processo de formação do médico. O objetivo seria formar profissionais com formação geral, capazes de prestar uma atenção integral e humanizada às pessoas, de trabalharem em equipe, de saberem tomar decisões considerando não somente a situação clínica individual, mas o contexto em que vivem os pacientes, os recursos disponíveis e as medidas mais eficazes ${ }^{31}$. 
Desse modo, mudar a formação médica implicaria mudança de concepção sobre ensino-aprendizagem, mudança de concepções sobre saúde-doença, sobre a prática docentediscente e sobre a prática médica. Feuerwerker ${ }^{31}$ ainda acrescentou que são necessárias mudanças nas relações entre médicos e população, entre médicos e demais profissionais da saúde, nas relações de poder entre departamentos e disciplinas, e também nas relações da universidade com os serviços de saúde, do território local, além de mudanças no espaço social, no campo das políticas.

Pelas falas dos gestores e docentes-tutores percebe-se a presença de algumas mudanças diretamente relacionadas com o novo currículo em ABP.

$\mathrm{Na}$ fala de um gestor, os docentes passaram por um processo de mudança de concepção e da prática com a ABP - processo este que envolveu reflexão sobre sua prática e concepção -, passaram a fazer a sua prática sem serem meramente uma cópia ou reprodução de como foram ensinados, e, por sua vez, os estudantes também o fizeram. Pelo menos, uma parte dos docentes deixou de pensar "se sei fazer, sei ensinar".

Os docentes se preocupavam em como os estudantes aprenderiam e quais seriam suas novas funções no papel docente na ABP.

A fala de um docente confirmou o que Lima ${ }^{30}$ escreveu sobre a formação médica centrada na abordagem biológica e o desafio para uma formação na abordagem biopsicossocial: "[...] acredito que no ensino tradicional é muito centrado, principalmente nos últimos anos de medicina, fica centrado na doença. [...] acho que o PBL [ABP] seria uma tentativa para fortalecer essas questões mais humanas." Isto considerando que o estudante, ao entrar na faculdade de Medicina, ainda está mais sensibilizado com a questão afetiva e preocupado com o outro.

Os docentes-tutores destacaram aspectos relevantes para a formação profissional do médico e que podem ser trabalhados na ABP da Famema. Consideraram que o estudo por problemas possibilitaria o estudo integrado sobre a pessoa nas dimensões biológica, psicológica e social. Mas um dos docentes-tutores alertou para o fato de que a integração dessas dimensões poderia estar ocorrendo nas tutorias, porém não teria ocorrido na prática médica. Pode-se inferir que os docentes e estudantes, embora estivessem começando a mudar seu discurso e concepções sobre o processo saúde-doença, ainda não haviam mudado a ação e a prática médica.

Além disso, a visão ampliada da pessoa parece se referir apenas ao patológico, sem considerar os aspectos saudáveis da pessoa. Acreditamos que, no fazer médico, deve-se valorizar o lado saudável do paciente como um aspecto positivo entre outros negativos presentes no ser humano, como estra- tégia de fortalecimento da auto-estima e, por sua vez, do autocuidado.

Os estudantes valorizaram a integração das três dimensões nos problemas que simulavam a realidade, apesar de alguns deles não conseguirem valorizar a dimensão social, o que, talvez, fosse uma das razões de se sentirem impotentes. Como eram adolescentes e de classe socioeconômica diferente da maioria dos pacientes, lidar com a complexidade dessa dimensão seria algo a ser construído ao longo do curso, o que pode ser facilitado pelo tutor.

Outro aspecto considerado relevante na formação médica, tanto para docentes quanto para estudantes, foi o aprender a aprender, de forma contínua para toda a vida. A transmissão de conteúdo cede sua importância ao desenvolvimento da capacidade de buscar as informações, selecioná-las, utilizá-las na aplicação do problema e avaliar o próprio processo de aprendizagem.

Os estudantes da 1a série que se sentiam adaptados à $\mathrm{ABP}$ percebiam benefícios com este método no que diz respeito à mudança de hábito para estudar, aprender a pesquisar e aprender que sempre terão de aprender. Relataram que desenvolveram autonomia para aprender e melhoraram sua autoconfiança.

O trabalho em grupo e em equipe foi outro aspecto relevante destacado por docentes e estudantes. Estes foram mais otimistas do que os próprios docentes quanto ao trabalho em equipe, porque, na prática, os docentes encontravam vários desafios.

Outras habilidades além dessas foram consideradas importantes para a formação do médico, tais como as de raciocínio crítico e clínico, e de comunicação - habilidades necessárias nesse cenário de grande fluxo de informações, pesquisas e avanço científico e tecnológico. A comunicação foi apontada pelos entrevistados como uma área deficitária na formação médica. Venturelli ${ }^{32}$ considera fundamental a comunicação na relação médico-paciente para o cuidado das pessoas e a humanização na formação médica.

O desafio de atingir uma visão mais ampla do paciente/ pessoa é um aspecto ainda apresentado pelos entrevistados na ABP da Famema, resquício provavelmente de uma formação pautada na concepção centrada no biológico, com um fazer voltado para o aspecto orgânico e patológico do paciente, visto que, nas tutorias, não se conseguiu ainda atingir a integração biopsicossocial e das disciplinas.

\section{CONSIDERAÇÕES FINAIS}

A prática da $\mathrm{ABP}$ em pequenos grupos de tutoria e a utilização de problemas que simulam a realidade, desde a 1a série, 
permitem os primeiros ensaios com a realidade do profissional médico, com vantagens: a teorização dos problemas, o trabalho em grupo, o estabelecimento de novas relações interpessoais (lidar com os novos papéis do professor e do estudante no pequeno grupo, mudança de atitudes frente ao grupo) e alterações nos hábitos de estudos dos estudantes.

A tutoria propicia também a proteção que nem sempre a prática profissional permite, pois sabemos que o problema simulado não está acontecendo de fato na interação do estudante com a prática profissional. Isto facilita ao estudante não entrar em contato com as emoções e ser mais racional, sem se dedicar à aprendizagem relativa à dimensão afetiva. Este, no entanto, é um dos limites das sessões de tutoria, ou seja, a dimensão psicológica no aspecto emocional em relação ao paciente e à família fica distante. Nada substitui a prática com os pacientes e as famílias.

Em 2003, foi implementada a Unidade de Prática Profissional desde a 1a série, com o objetivo de propiciar maior integração, responsabilização e vínculo dos estudantes com as famílias que iriam acompanhar por dois anos. Eles interviriam na prática, e o contato com a família não seria apenas um cenário de aprendizagem, mas de ação social, com parcerias da academia com os serviços de saúde e a comunidade.

O currículo em ABP na Famema continua em construção permanente. Em 2004, estava mais próximo da aprendizagem baseada na prática profissional com a utilização de problemas vivenciados por estudantes na prática e que passaram a ser estudados na tutoria.

Esta pesquisa, ao dirigir a atenção para as concepções sobre a ABP, possibilitou-nos identificar que tanto estudantes quanto docentes começavam a questionar o ensino-aprendizagem centrado no professor, no saber do professor, no conteúdo disciplinar e na reprodução dos conteúdos por memorização. Significou ouvir docentes que iniciaram a ABP, muitas vezes, sem uma exata compreensão e que, após essa experiência, alteraram sua concepção do processo de ensino-aprendizagem, conseguindo reconhecer que o que a escola pode ensinar de melhor é o aprender a aprender, porque a escola nunca deu e nem vai dar conta de socializar todos os conhecimentos.

O processo de educação permanente que está ocorrendo na Famema pode ajudar diretamente estes docentes-tutores que ainda hoje se mostram inseguros ou céticos em suas ações ou intervenções no processo tutorial. É um espaço de reflexão sobre suas práticas, e um cuidado especial deve ser dedicado a estes profissionais que antes eram responsáveis por suas disciplinas e trabalhavam sozinhos, sem articulação com as outras disciplinas. Hoje, eles constroem juntos suas ações e desenvolvem um processo de auto-avaliação constante. Existe ainda aquele docente que não aceita totalmente este processo de ensino-aprendizagem nas tutorias. Lidar com as oposições e diferenças é algo que sempre fará parte da nossa prática. Encontrar estratégias para lidar com isso é papel da instituição.

Acreditamos que a prática e a reflexão crítica podem propiciar mudanças nas concepções de ensino-aprendizagem e no fazer, seja no fazer das tutorias, seja no fazer da prática médica, como sujeitos sociais. Acreditamos que esta reflexão possa se pautar pelo objetivo maior que é o perfil do médico que a Famema pretende formar, coerente com as Diretrizes Curriculares nacionais do curso médico ${ }^{3}$.

A construção coletiva e permanente do currículo em ABP na Famema permanece um desafio, porque, embora existam alguns espaços de construção e reflexão organizados, nem sempre são utilizados por todos os docentes e estudantes.

Estudos futuros também poderão mostrar as prováveis alterações das concepções dos estudantes iniciantes em ABP e as daqueles de maior experiência com esse método de ensinoaprendizagem no final do curso. Isto porque alguns estudantes entrevistados neste estudo já mostraram mudanças com a $\mathrm{ABP}$ do primeiro semestre para o segundo semestre do curso, num processo de adaptação.

Este trabalho pode ajudar os estudantes ingressantes na Famema a desmistificar um pouco o novo, sendo acolhidos com as experiências dos outros e as nossas. A Famema precisa olhar com atenção aqueles que ainda se sentem inseguros e perdidos no segundo semestre da 1a série. A autonomia desses estudantes precisa ser assistida e construída de maneira colaborativa por quem os recebe.

O fortalecimento da educação permanente junto aos docentes e profissionais de saúde é um espaço fundamental para apoiar a transformação da prática profissional e indica, por parte da Famema, um cuidar especial daqueles que trabalham vinculados ao projeto político-pedagógico, com todas as suas emoções e saberes na formação de um profissional generalista, humano, ético, crítico, reflexivo e sempre em busca de aprender para exercer o seu fazer, o seu ser, ao lado de outras pessoas.

\section{REFERÊNCIAS}

1. Pontes RHP. Reforma Curricular no Ensino Médico: estudo de caso de uma escola de medicina. [Tese] São Paulo:Faculdade de Saúde Pública/ Universidade de São Paulo; 2001.

2. Comissão Interinstitucional Nacional de Avaliação do Ensino Médico. In: Santos R C, Piccini R, Fachhini L A Org. Proposta:preparando a transformação da educação médi- 
ca brasileira:projeto CINAEM III fase: relatório 1999-2000. Pelotas: UFPel; 2000 [p.279-289].

3. Brasil. Ministério da Educação. Conselho Nacional de Educação. Parecer CNE/CES 1.133/2001, de 7 de agosto de 2001: Diretrizes curriculares nacionais dos cursos de graduação em enfermagem, medicina e nutrição. Brasília; 2001. Disponível em http://www.mec.gov.br/Sesu/ diretriz.shtm. [Acesso em: 29 outubro 2004].

4. Angeli OA. A aprendizagem baseada em problemas e os recursos adaptativos de estudantes de um curso médico. [Tese] Ribeirão Preto: Faculdade de Medicina de Ribeirão Preto/ Universidade de São Paulo; 2002.

5. Santos SR. O aprendizado baseado em problemas (Problem-Based Learning - PBL). Rev. Bras. Educ. Med. 1994; 18(3): 121-124.

6. PBL Directory. .Disponível em: http://interact.bton.ac.uk/ /pbl/index.php. [Acesso em: 2 novembro de 2004.

7. Komatsu RS, Zanolli, MB, Lima VV. Aprendizagem baseada em problemas. In: Marcondes E, Gonçalves EL, coord. Educação Médica. São Paulo: Savier; 1998. p. 223-237.

8. Coll C. Psicologia e currículo: uma aproximação psicopedagógica a elaboração do currículo escolar. São Paulo: Ática; 2000.

9. Barrows HS, Tamblyn RM. Problem-based learning. New York: Springer; 1980.

10. Faculdade de Medicina de Marília. Guia do processo de ensino-aprendizagem: "aprender a aprender". São Paulo: Faculdade de Medicina de Marília; 2002.

11. Mamede S. Aprendizagem baseada em problemas: características, processos e racionalidade. In: Mamede $S$, Penaforte J, org. Aprendizagem baseada em problemas: anatomia de uma nova abordagem educacional. Fortaleza: Hucitec;2001. p. 25-48.

12. Charlin B, Mann K, Hansen P. The many faces of problembased learning: a framework for understanding and comparison. Med Teach. 1998; 20(4): 323-330.

13. Brandon JE, Majumbar B. An introduction and evaluation of problem-based learning in health professions education. Family \& Community Health 1997; 20 (1): 1-15.

14. Frost M. An analysis of the scope and value of problembased learning in the education of health care professionals. J Adv Nurs. 1996; 24(5): 1047-1053.

15. Vernon DTA, Blake RL. Does problem-based learning work? A meta-analysis of evaluative research. Academic Medicine 1993; 71(11): 550-563.
16. Albanese MA, Mitchell S. Problem-based learning: a review of literature on its outcomes and implementation issues. Academic Medicine 1993; 68(1): 52-81.

17. Norman GR, Schmidt HG. The psychological basis of problem-based learning: a review of the evidence. Academic Medicine 1992; 67(9): 557-565.

18. Norman GR, Schmidt HG. Effectiveness of problem-based learning curricula: theory, practice and paper darts. Med Education. 2000; 34(9): 721-728.

19. Colliver JA. A effectiveness of problem-based learning curricula: research and theory. Academic Medicine 2000; 75(3): 259-266.

20. Kaufman DM, Mann KV. Basic sciences in problem-based learning and conventional curricula: students' attitudes. Med. Education 1997; 31(3): 177-180.

21. Richards BF et al. Ratings of sutdents' performances in a third-year internal medicine clerkship: a comparison between problem-based and lecture-based curricula. Academic Medicine 1996; 71(2): 187-189.

22. Das et al. Self and tutor evaluations in problem-based learning tutorials: is there a relationship? Med Education 1998; 32(4): 411-418.

23. Thomas RE. Problem-based learning: measurable outcomes. Med.Education 1997; 31(5): 320-329.

24. Almeida MJ. A educação médica e as atuais propostas de mudança: alguns antecedentes históricos. Rev. Bras. Educ. Med. 2001; 25(2): 42-52.

25. Komatsu RS. Aprendizagem baseada em problemas na Faculdade de Medicina de Marília: sensibilizando o olhar para o idoso. [Tese] Marília, Faculdade de Filosofia e Ciências, Universidade Estadual Paulista "Júlio de Mesquita Filho" ;2003.

26. Manzini EJ. Considerações sobre a elaboração de roteiro para entrevista semi-estruturada. In: Marquezine MC, Almeida MA, Omote S, org. Colóquios sobre pesquisa em Educação Especial. Londrina: Eduel; 2003, p.11-25.

27. Bardin L. Análise de conteúdo. Lisboa: Edições 70;1979.

28. Fagundes AJF. Descrição, definição e registro do comportamento. São Paulo: Edicon; 1999.

29. Barrows HS. The tutorial process. Springgfield: University School of Medicine;1988.

30. Lima VV. Educação Médica: a dimensão social no currículo do curso da Faculdade de Medicina de Marília em 1998 e 1999. [Tese] São Paulo: Faculdade de Saúde Pública da Universidade de São Paulo; 2000. 
31. Feuerwerker LC Além do discurso de mudança na educação médica: processos e resultados. São Paulo: Hucitec; 2002.

32. Venturelli L. Education medica: nuevos enfoques, metas y metodos. Washington: Organizacion Panamericana de la Salud-OPAS/PAHO; 1997.

\section{Conflito de Interesse}

Declarou não haver.

\section{Endereço para correspondência}

Magali Aparecida Alves de Moraes

Rua Orlando Righetti, 212 - Fragata

17519-230 - Marília - SP

e-mail: dmagali@flash.tv.br

Eduardo José Manzini

Rua Guanás, 70 - apto 154

Marília - 17502-560 - SP

e-mail: manzini@marilia.unesp.br 